\title{
Robust Control of Series Active Power Filters for Power Quality Enhancement in Distribution Grids: Simulation and Experimental Validation
}

\author{
T. Toumi, A. Allali, A. Meftouhi, O. Abdelkhalek, A. Benabdelkader, M. Denaï
}

\begin{abstract}
This paper presents a simulation study and an experimental implementation of a single-phase Series Active Power Filter (SAPF) for the mitigation of harmonics in the load voltage. The aim is to regulate the injection voltage of the SAPF to compensate the grid voltage via the injection transformer in addition to maintaining the load voltage stable. The control strategies investigated in this work include Backstepping Sliding Mode Control (BSMC) and a neuro-fuzzy controller based on ANFIS (Adaptive Neuro-Fuzzy Inference System) 1. The proposed control strategies for the single-phase SAPF are initially evaluated in simulations under MATLAB/Simulink and then validated on a laboratory-scale hardware experimental set up consisting of a source and a single-phase SAPF. A comparative study of these controllers with respect to their performance and robustness in mitigating power quality against voltage disturbances and harmonics is presented. Both simulation and experimental results have demonstrated that ANFIS-based controller was able to achieve superior performance and a lower total harmonic distortion (THD) as compared to the other control methods.
\end{abstract}

Keywords: Single-phase series active power filter (single-phase SAPF), Backstepping sliding mode control, ANFIS, DSpace, harmonic distortion.

\section{INTRODUCTION}

In recent years, power quality issues have become a vital concern for both the utility and end-users. This is due to the widespread use of nonlinear loads and modern power electronics devices in various domestic and industrial applications, such as electrical motor drives, power supplies, induction heating, electronic lighting, etc., [1-3]. These electronic and solid-state-based devices generate current harmonics which are injected into the distribution network and cause voltage disturbances at different points of the network.

Electric equipment connected at these points is directly affected by these harmonics and negative effects, notably a distortion in the voltage, may appear instantaneously or occur later. Harmonics can also cause overheating of electric cables as well as a disruption in the operation of certain electrical equipment or even cause a complete shutdown of certain machinery $[4,5]$. The limits on harmonics levels were established by IEC61000 standards, and IEEE Std. 519-1992 [6].

Passive filters are traditionally used to mitigate harmonic distortion and have long been employed in the industrial and utility sectors [7]. However, passive filtering has several drawbacks including the lack of adaptation during variations of the load and network impedance. Furthermore, passive filters may cause resonance with network and in some cases this latter, when excited, can cause large harmonics in the voltage and current of the filter capacitor and the network [8-10]. Unlike passive filters, modern Active Power Filters (APFs) are power electronic-based devices which offer superior filtering performance and have faster transient response. They can compensate for current and voltage harmonics, reactive power and provide voltage control in the distribution network [11]. APFs are basically classified into two types: Shunt, parallel and series APFs. Shunt active filters are connected in parallel 
and inject into the network a current that is equal in amplitude to the harmonic current to be suppressed but with opposite phase. Series active filters, on the other hand, are connected in series with the network voltage via a matching transformer and behave like a voltage generator which imposes a harmonic voltage such that, when added to network voltage, produce a sinusoidal-like voltage waveform at the connection point $[12,13]$. SAPF can compensate for voltage disturbances acting on the load side [14].

The aim of this work was to propose robust control strategies to improve the performance of the SAPF for the mitigation of harmonics in the presence of nonlinear loads in the network. Backstepping Sliding Mode Control (BSMC) is a switching type of control which can cope with nonlinearities, parameter uncertainties and disturbances and therefore can be considered as a suitable candidate for this application. ANFIS offers the desired robustness and learning ability to enhance the performance of the SAPF in dealing harmonics and can operate under various operating conditions.

This paper presents an analysis, a simulation study, and an experimental validation of three controllers for a SAPF to mitigate voltage disturbances and improve the power quality in the distribution network.

The remaining of the paper is organized as follows: Section 2 introduces the basic circuits of the SAPF and derives the control methods proposed in this work including Backstepping Sliding Mode Controller (BSMC) and an Adaptive Neuro-Fuzzy Inference System (ANFIS)-based controller. Section 3 presents the simulation results and discussions. In Section 4, the experimental prototype of the SAPF is described and the experimental results are presented under different voltage disturbance conditions. Finally, Section 5 summarizes the conclusions of this paper.

\section{MODELING OF THE SAPF SYSTEM}

The overall structure of the SAPF is represented by the converter circuit depicted in Fig. 1. Kirchhoff's voltage law gives [15]:

$$
\begin{aligned}
& v_{t}=R_{f} i_{L}+L_{f} \frac{d i_{L}}{d t}+V_{i n j} \\
& V_{i n j}=\frac{1}{C_{f}} \int i_{c} d t
\end{aligned}
$$

Where $v_{t}$ is the output inverter voltage, $V_{i n j}$ is the SAPF output voltage, $V_{d c}$ represents the voltage of the DC link, $i_{L}$ and $i_{C}$ are the currents flowing the inductor and capacitor filter respectively, $L_{f}, C_{f}$ are the inductance and capacitance of the filter, $R_{f}$ represent the inductor equivalent series resistance.

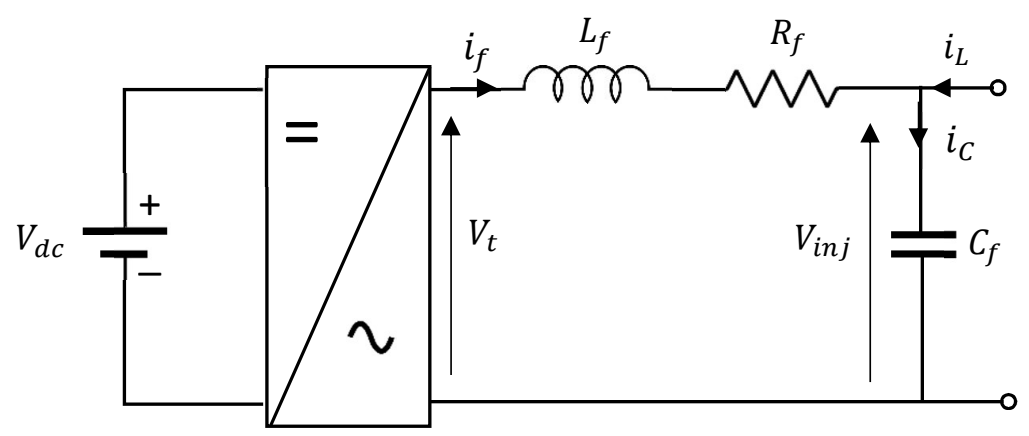

Fig. 1: Equivalent circuit of the SAPF.

Taking Laplace of (1) and (2), the system is described by the following equation: 


$$
V_{i n j}(s)=\frac{1}{1+R_{f} C_{f} s+L_{f} C_{f} s^{2}} V_{t}(s)+\frac{L_{f} s+R_{f}}{1+R_{f} C_{f} s+L_{f} C_{f} s^{2}} I_{L}(s)
$$

Where $V_{i n j}(s), V_{t}(s)$ and $I_{L}(s)$ represent the Laplace transforms and $s$ denotes the Laplace operator.

\section{PROPOSED CONTROL STRATEGIES FOR THE SINGLE-PHASE SAPF}

Fig. 2 depicts the basic control scheme of the SAPF. The control scheme is based on a closed-loop control which regulates the injected voltage of the SAPF via an IGBT Voltage Source Inverter (VSI) driven by a Pulse Width Modulation (PWM) control strategy [16,17].

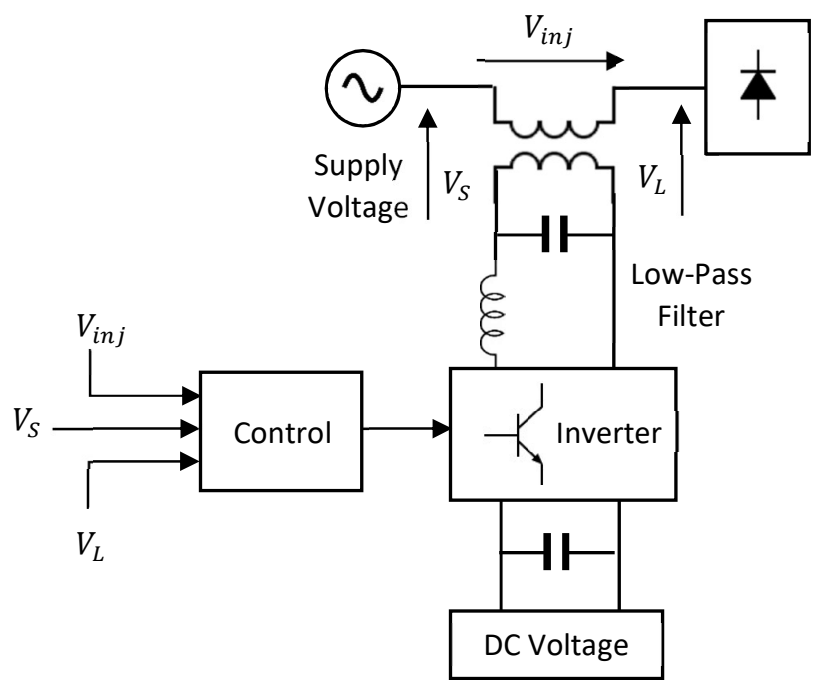

Fig. 2 Diagram of the SAPF and its control system.

Two control strategies are implemented in this work namely BSMC and ANFIS. The aim of these controllers is to regulate the injected voltage of the single-phase SAPF.

\subsection{Backstepping sliding mode controller design}

Consider the following state-space model:

$$
\left\{\begin{array}{l}
\frac{d V_{i n j}}{d t}=\frac{1}{C_{f}} i_{f}-\frac{1}{C_{f}} i_{S} \\
\frac{d i_{f}}{d t}=-\frac{1}{L_{f}} V_{i n j}-\frac{R_{f}}{C_{f}} i_{f}+\frac{1}{L_{f}} V_{d c} u
\end{array}\right.
$$

Where $u$ denotes the control output.

The backstepping control strategy is designed in two steps [18-20]:

Step 1: Design of the virtual control function

The tracking error is defined as follows [21-23]:

$$
z_{1}=x_{1}-z_{r}
$$

Then the time derivative of $z_{1}$ is given by, 


$$
\dot{\mathrm{z}}_{1}=x_{2}-\dot{\mathrm{z}}_{\mathrm{r}}
$$

Where $z_{r}$ is a reference voltage and the injected voltage and its derivative as $V_{i n j}=x_{1}$ and $\dot{x}_{1}=x_{2}$ respectively. Then, the model becomes:

$$
\left\{\begin{array}{l}
\dot{x}_{1}=x_{2} \\
\dot{x}_{2}=-\frac{1}{L_{f} C_{f}} x_{1}-\frac{R_{f}}{L_{f} C_{f}} x_{2}-\frac{R_{f}}{L_{f} C_{f}} i_{s}-\frac{1}{C_{f}} \frac{d i_{s}}{d t}+\frac{V_{d c}}{L_{f} C_{f}} u
\end{array}\right.
$$

Define a virtual control function as

$$
\alpha_{1}=C_{1} z_{1}
$$

where, $C_{1}$ is a positive constant.

By taking an auxiliary tracking error variable,

$$
z_{2}=\dot{z}_{1}-\alpha_{1}
$$

Now, define the first Lyapunov function as

$$
V_{1}=\frac{1}{2} z_{1}^{2}
$$

Then the time derivative of $V_{1}$ becomes,

$$
\dot{V}_{1}=z_{1} \dot{z}_{1}=z_{1}\left(z_{2}-\alpha_{1}\right)=z_{1}\left(z_{2}-C_{1} z_{1}\right)=z_{1} z_{2}-C_{1} z_{1}{ }^{2}
$$

Step 2: define second augmented Lyapunov function and sliding surface

$$
V_{2}=V_{1}+\frac{1}{2} S^{2}
$$

Where $S$ is the sliding surface given by:

$$
S=C_{2} z_{1}+z_{2}
$$

Using Equations (12) and (13), the first derivative of $V_{2}$ is defined as follows:

$$
\dot{V}_{2}=\dot{V}_{1}+S \dot{S}=z_{1} z_{2}-C_{1} z_{1}^{2}+S\left[C_{2}\left(z_{2}-C_{1} z_{1}\right)-\dot{z}_{2}\right]
$$

The derivative of $z_{2}$ with respect to time is given by:

$$
\begin{aligned}
\dot{z}_{2} & =\ddot{z}_{1}-\dot{\alpha}_{1}=\ddot{x}_{1}-\ddot{z}_{r}+\dot{\alpha}_{1} \\
& =-\frac{1}{L_{f} C_{f}} x_{1}-\frac{R_{f}}{L_{f} C_{f}} x_{2}-\frac{R_{f}}{L_{f} C_{f}} i_{s}-\frac{1}{C_{f}} \frac{d i_{s}}{d t}+\frac{V_{d c}}{L_{f} C_{f}} u-\ddot{z}_{r}+\dot{\alpha_{1}}
\end{aligned}
$$

Then,

$$
\dot{S}=C_{2}\left(z_{2}-C_{1} z_{1}\right)-\frac{1}{L_{f} C_{f}} x_{1}-\frac{R_{f}}{L_{f} C_{f}} x_{2}-\frac{R_{f}}{L_{f} C_{f}} i_{s}-\frac{1}{C_{f}} \frac{d i_{s}}{d t}+\frac{V_{d c}}{L_{f} C_{f}} u-\ddot{z}_{r}+\dot{\alpha_{1}}
$$

Then, we impose 


$$
\dot{S}=f(S) * H \operatorname{sgn}(S)
$$

Where, $H>0$

$$
f(S)=-[1 / \mathrm{q}(S)]
$$

And $q(S)$ is given by:

$$
q(S)=\left[\gamma+(1-\gamma) e^{-\alpha|S|} \cos (\beta|S|)\right]
$$

The sliding mode occurs if $S=\dot{S}=0$. Then, the control law is finally obtained as:

$$
u=\frac{L_{f} C_{f}}{V_{d c}}\left[\ddot{z}_{r}+\frac{1}{L_{f} C_{f}} x_{1}+\frac{R_{f}}{L_{f}} x_{2}+\frac{R_{f}}{L_{f} C_{f}} i_{s}+\frac{1}{C_{f}} \frac{d i_{s}}{d t}-\dot{\alpha}_{1}-C_{2}\left(z_{2}-C_{1} z_{1}\right)+\left[\frac{\operatorname{Hsgn}(S)}{q(S)}\right]\right]
$$

\subsection{ANFIS-based control design for the single-phase SAPF}

ANFIS has been proposed by Jang in 1993 [24-27]. It combines the learning capability of artificial neural networks (ANN) with the knowledge representation and reasoning ability of fuzzy systems. ANFIS uses a hybrid learning algorithm which combines least-squares estimation and the gradient-descent method. During training, each epoch is performed in two steps. In the forward pass, the output consequent parameters are estimated using simple Least Squares. Once the output consequent parameters are estimated, the network output is evaluated, and the error is then determined. In the backward pass, the antecedent parameters are updated using the gradient descend algorithm according to the chain rule. A brief definition of ANFIS layers structure is given in Appendix A.

The design of the ANFIS-based controller is performed with the Fuzzy Logic Toolbox of MATLAB. The data used to train ANFIS controller was obtained from the transient response of the system with a PI controller (error and control signal). The design methodology followed consisted of training ANFIS model to work as controller. We used the input and output data (i.e. error and control signal) from the PI controller designed for the SAPF to train ANFIS. We have performed extensive simulations in order to obtain the optimal PI controller gains $K_{p}, K_{i}$ and $K_{d}$ which produced the desired transient response. Although ANFIS has been trained with PI, the resulting controller has superior performance and robustness as compared to the original PI. The ANFIS controller obtained has better response characteristics such as shorter settling time and faster rise time than a PI controller. The neurofuzzy features of ANFIS provide it with the ability to learn and adapt to new operating conditions which the original PI cannot handle and must be re-tuned to cope with the new parameters of the system.

The inputs to ANFIS controller are the error $\varepsilon(k)$ and error change $\Delta \varepsilon(k)$ defined as:

$$
\begin{aligned}
& \varepsilon(k)=V_{r e f}-V_{i n j} \\
& \Delta \varepsilon(k)=\varepsilon(k)-\varepsilon(k-1)
\end{aligned}
$$

Where $V_{r e f}$ is the reference voltage, $V_{\text {inj }}$ is the injected voltage. The membership functions of the error $\varepsilon$ and error change $\Delta \varepsilon$ are defined as triangular membership functions M1, M2 and M3 are shown in Figs. 3 and 4 respectively. The fuzzy inference system (FIS) of the Sugeno type is modeled by constructing nine rules using three linguistic variables for the ANFIS controller. 


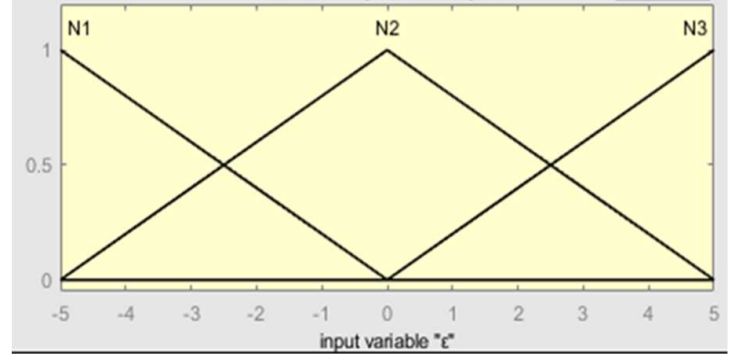

Fig. 3 Membership function of $\varepsilon$.

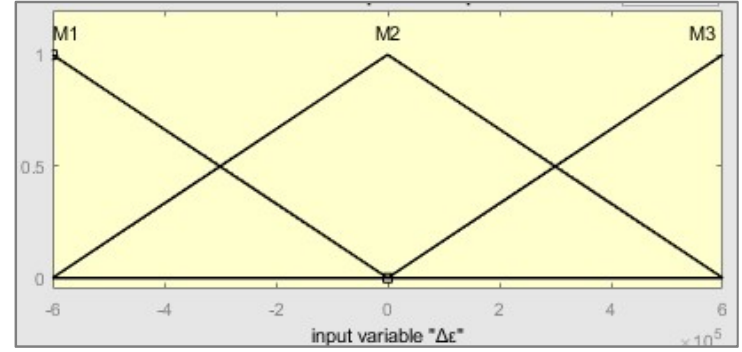

Fig. 4 Membership function of $\Delta \varepsilon$.

The output variable $Y$ given by ANFIS training is a vector of constants $Y=\left[\boldsymbol{y}_{\mathbf{1}}, \boldsymbol{y}_{\mathbf{2}}, \boldsymbol{y}_{\mathbf{3}}, \boldsymbol{y}_{\mathbf{4}}, \boldsymbol{y}_{\mathbf{5}}, \boldsymbol{y}_{\mathbf{6}}, \boldsymbol{y}_{\mathbf{7}}, \boldsymbol{y}_{\mathbf{8}}, \boldsymbol{y}_{\mathbf{9}}\right]$. The fuzzy rules are implemented as illustrated in Table 1. A compact representation of the controller rule base is given in Table 2 .

Table 1 Fuzzy rules.

\begin{tabular}{ccc}
\hline IF input is & And & THEN output is \\
\hline $\mathbf{N 1}$ & M1 & $y_{1}$ \\
\hline $\mathbf{N 1}$ & M2 & $y_{2}$ \\
\hline $\mathbf{N 1}$ & M3 & $y_{3}$ \\
\hline $\mathbf{N 2}$ & M1 & $y_{4}$ \\
\hline $\mathbf{N 2}$ & M2 & $y_{5}$ \\
\hline $\mathbf{N 2}$ & M3 & $y_{6}$ \\
\hline $\mathbf{N} 3$ & M1 & $y_{7}$ \\
\hline $\mathbf{N} 3$ & M2 & $y_{8}$ \\
\hline $\mathbf{N} 3$ & M3 & $y_{9}$ \\
\hline
\end{tabular}

Table 2: Fuzzy rule base representation.

\begin{tabular}{|c|c|c|c|}
\hline$\varepsilon-\Delta \varepsilon$ & M1 & M2 & M3 \\
\hline $\mathrm{N} 1$ & $y_{1}$ & $y_{2}$ & $y_{3}$ \\
\hline $\mathrm{N} 2$ & $y_{4}$ & $y_{5}$ & $y_{6}$ \\
\hline $\mathrm{N} 3$ & $y_{7}$ & $y_{8}$ & $y_{9}$ \\
\hline
\end{tabular}

The three-dimensional rule surface shown in Fig. 5 visualizes the variation of the output against the two input which are the error and change of error.

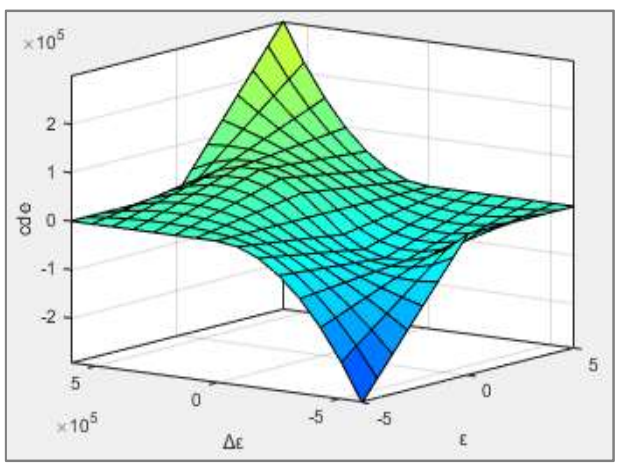

Fig. 5 Surface viewer of ANFIS. 


\section{SIMULATION RESULTS}

This section presents the simulations that have been undertaken to evaluate the performance of the BSMC and ANFIS-based control for the single-phase SAPF to reduce harmonics in the network. The parameters values employed in the model are listed in Table B.1 of Appendix B.

The single-phase SAPF model is implemented in MATLAB/Simulink. A detailed description of the Simulink models of the SAPF and BSMC control are given in Fig. C.1 and Fig. C.2 respectively (Appendix C). The proposed SAPF is interconnected to the distribution system, which is modelled as a single-phase power supply voltage $V_{S}$. The system has been simulated under several fault conditions including voltage disturbances (sags and swells) and harmonic distortions. The simulation results demonstrate the ability of the SAPF with the proposed control scheme to compensate for voltage disturbances and harmonics.

From Figs. 6 and 7, it can be noted that from time $t=0.2 \mathrm{~s}$, the single-phase SAPF begins to compensate for the harmonics in the voltage, by injecting compensating voltages which are synchronized in amplitude but with opposite phase to the source voltage.
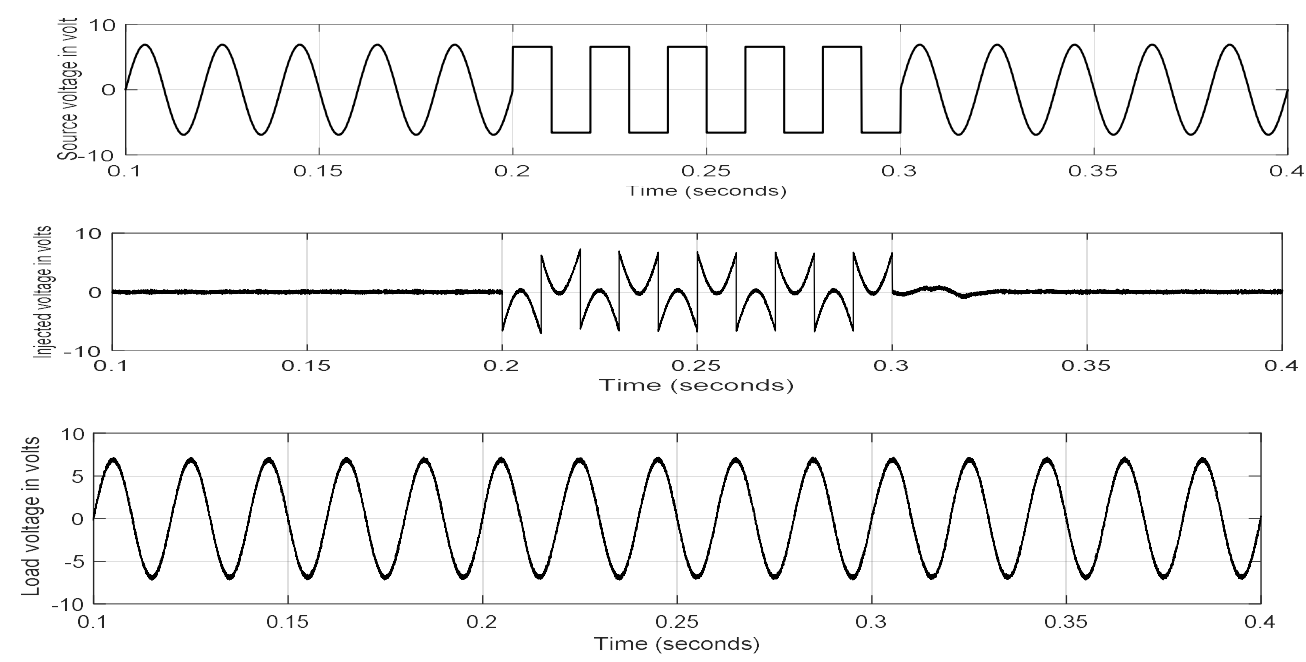

Fig. 6: Voltage waveforms with BSMC.
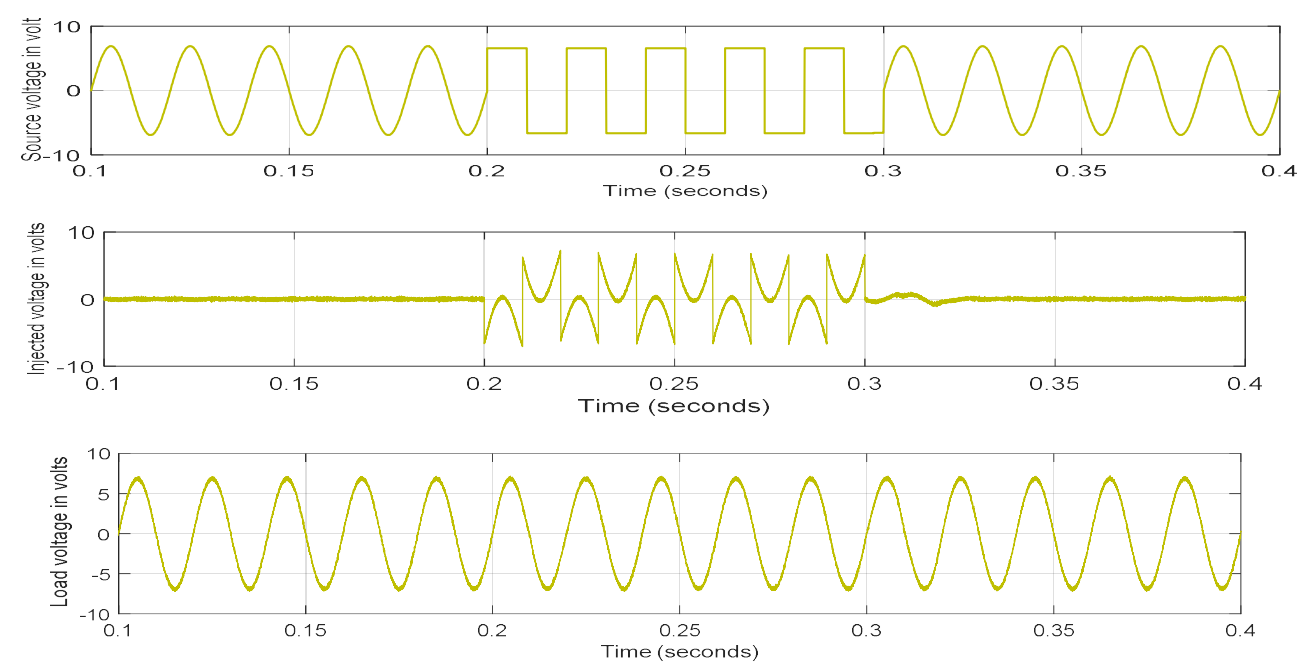
Fig.7: Voltage waveforms with ANFIS.

Based on the simulation results, the effectiveness of single-phase SAPF to improve energy quality and compensate for voltage disturbances has been demonstrated. The results obtained with BSMC and ANFIS controllers have shown good performance and robustness. This is reflected by THD levels that meet the IEEE standards. Figs. 8 and 9 present the total harmonic distortion (THD) results for BSMC and ANFIS-based controllers.

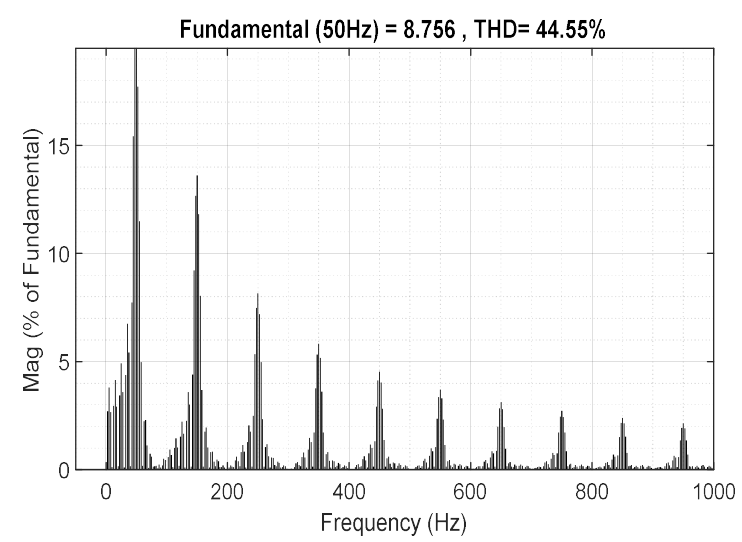

(a)

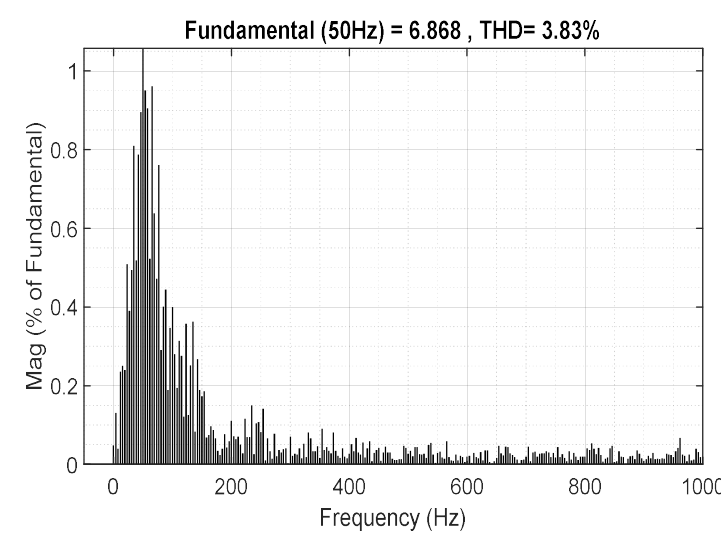

(b)

Fig. 8: Total harmonic distortion with BSMC (a) source voltage, (b) load voltage.

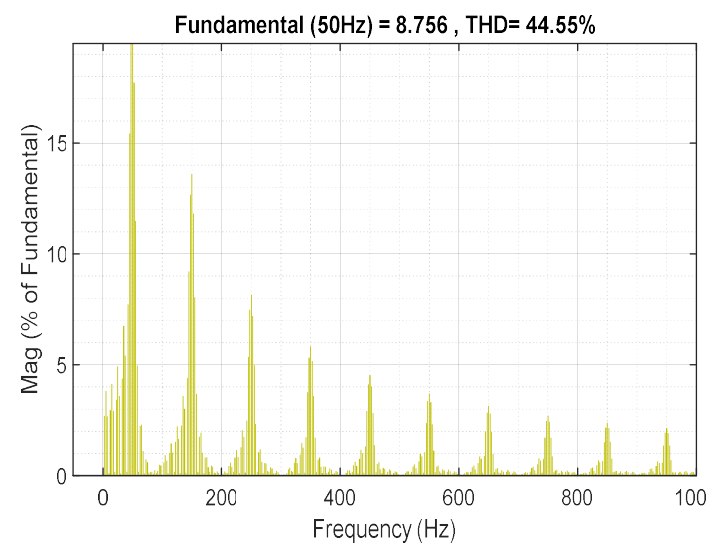

(a)

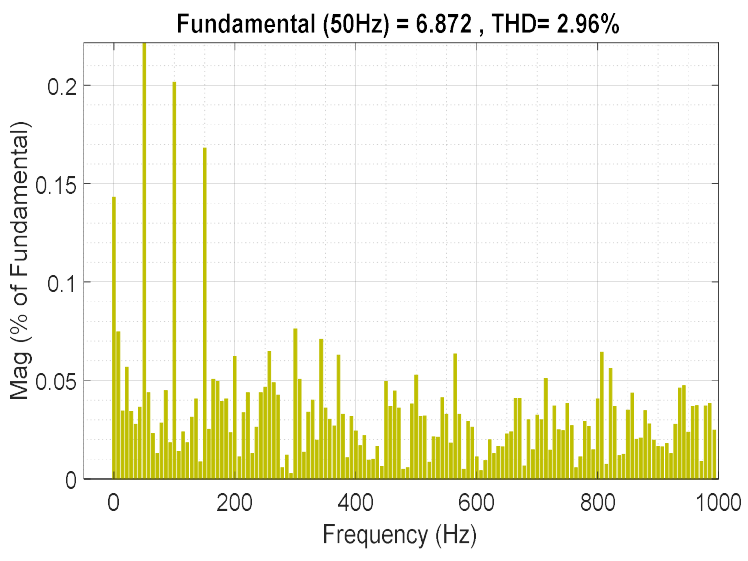

(b)

Fig. 9: Total harmonic distortion with ANFIS control (a) source voltage, (b) load voltage.

Table 3 presents a comparison between the THD values before and after harmonic voltage compensation for the two control methods proposed in this paper. 
Table 3: Comparison of the THD for the two controllers in the simulation tests.

\begin{tabular}{|c|c|c|}
\hline THD without control & \multicolumn{2}{|c|}{ THD with control } \\
\hline \multirow{2}{*}{$44.55 \%$} & BSMC & ANFIS \\
\cline { 2 - 3 } & $3.83 \%$ & $2.96 \%$ \\
\hline
\end{tabular}

\section{EXPERIMENTAL EVALUATION AND RESULTS}

This section presents the hardware used to design the experimental set-up of the SAPF and its auxiliary circuits. Fig. 10 shows the laboratory prototype of the system of the single-phase SAPF designed in this work for the mitigation of harmonics. The single-phase SAPF consists of the following components:

- An injection/booster transformer for injecting voltage during abnormal condition.

- A 20 kVA three-phase IGBT Inverter SKM 100 GB 123 D, rated $1200 \mathrm{~V}$ and $90 \mathrm{~A}$ and one antiparallel diode. The power switches are turned on and off using $+5 \mathrm{~V}$ and $-5 \mathrm{~V}$ voltage pulse respectively.

- Voltage regulators.

- A power and energy analyzer ca-8335-qualistar

- A driver hcp13120 from Agilent Technologies generates PWM signals. The driver circuit is supplied from $\pm 15 \mathrm{~V}$.

- A non-linear load.

- Voltage sensors.

- A dSPACE DS1104 board running under the integrated development environment of MATLAB/Simulink RTW, implements the controllers and generate the PWM signals for the converters.

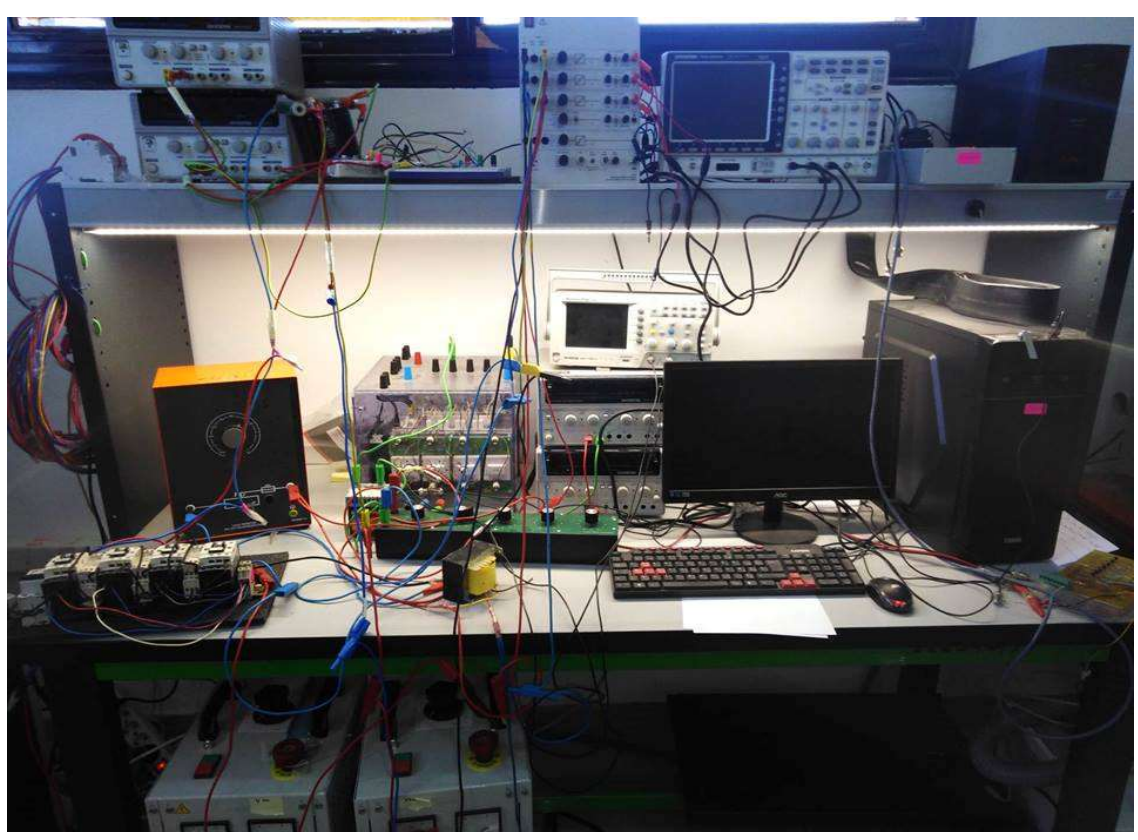

Fig. 10: Experimental setup of the SAPF circuit. 
The proposed SAPF should be able to compensate for the problem of voltage harmonics that occur frequently in a single-phase distribution system. The single-phase SAPF injects the required voltage so that the magnitude of the load voltage is maintained constant and is not distorted.

The PWM switching frequency was set at $15 \mathrm{kHz}$. A resistive load has been used in these experimental tests. As can be seen from the results, the SAPF system was able to effectively attenuate the harmonics in the network voltage waveform and which are supplied to the load. These harmonics appear between $t=5.6 \mathrm{~s}$ and $\mathrm{t}=6.3 \mathrm{~s}$. The waveforms of the compensated voltage, load voltage and the injection voltage for BSMC and ANFIS controllers are presented in Fig. 11 and 13 respectively. Figure 12 and 14 shows the THD of the compensated voltage without and with SAPF. The parameter values used in the simulation model are identical to those of the experimental prototype. Depending on the waveform of the injected voltage, the proposed control scheme successfully generated the desired voltage with a waveform like the highly distorted source voltage.

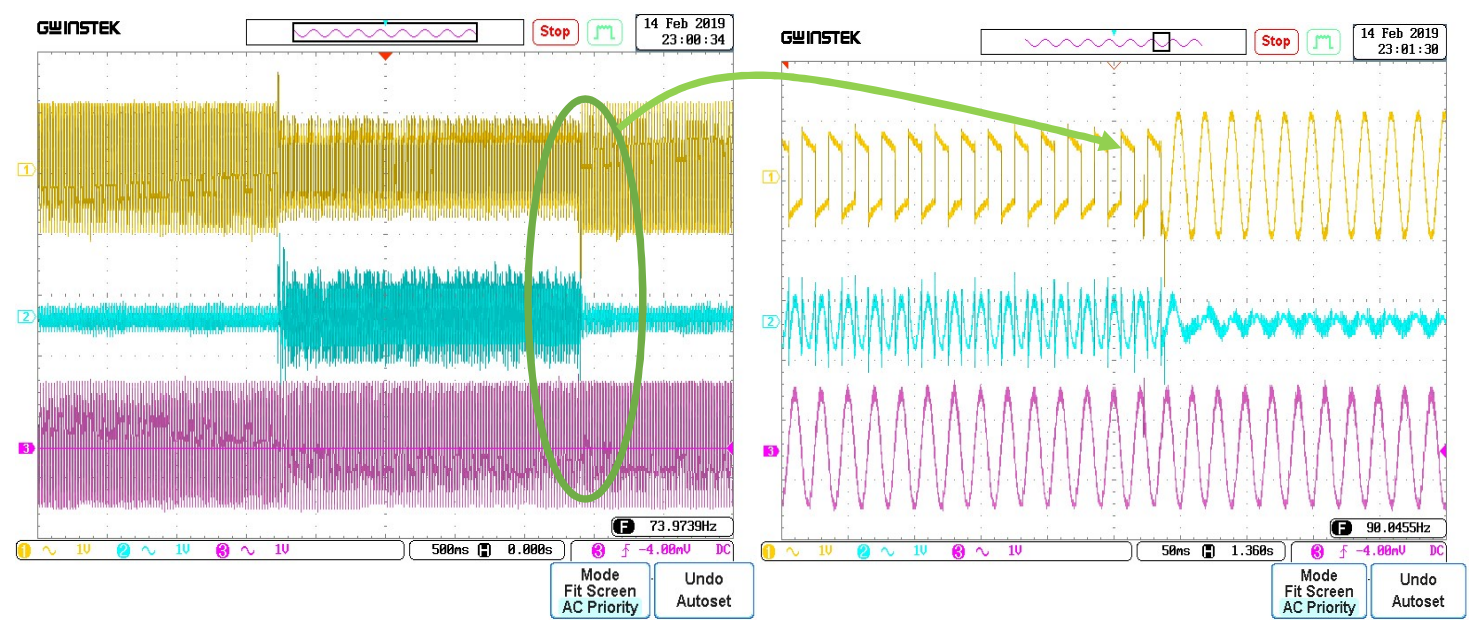

Fig. 11: Harmonic voltage compensation with BSMC.

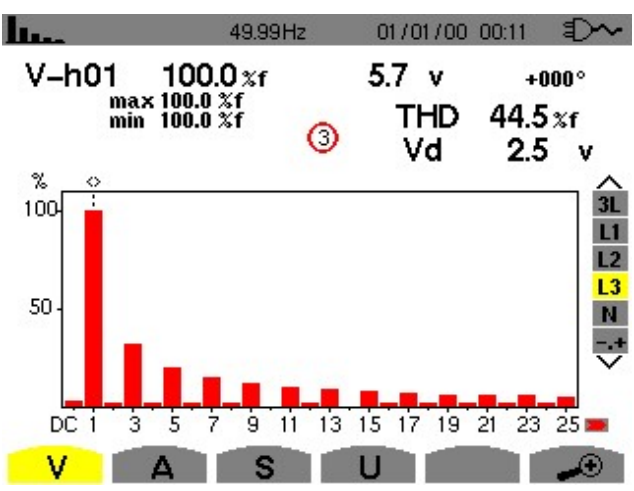

(a)

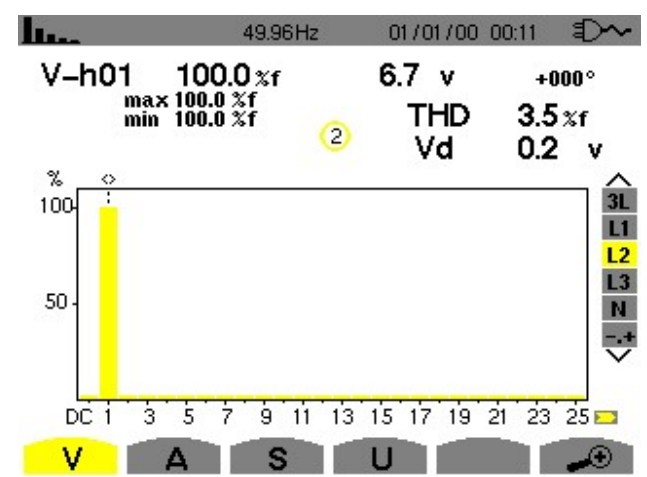

(b)

Fig. 12: Total harmonic distortion with BSMC: (a) source voltage, (b) load voltage. 

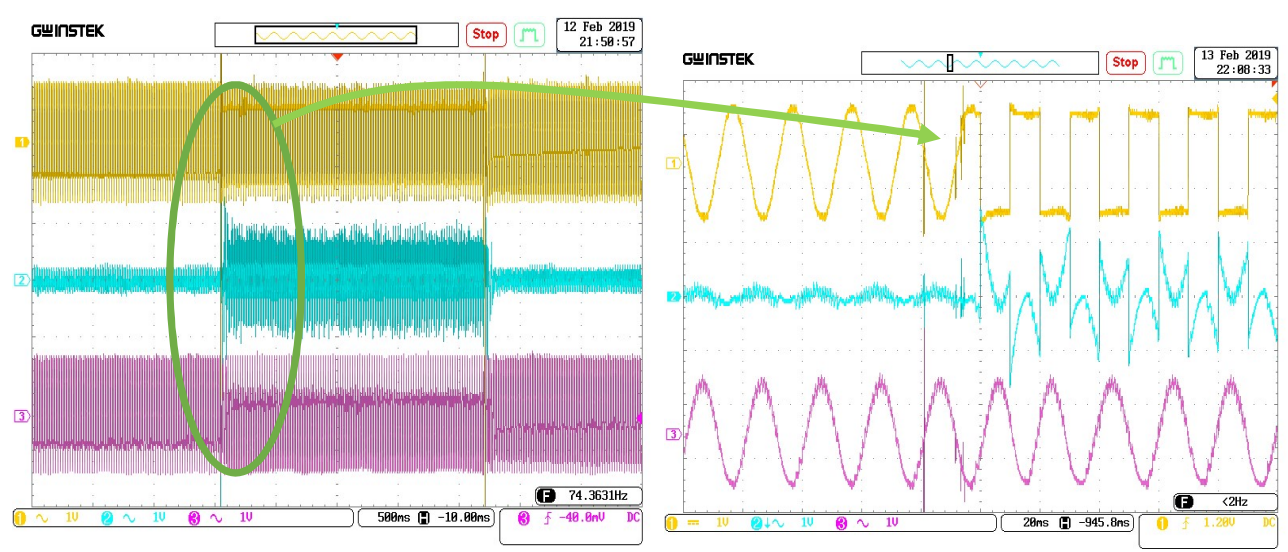

Fig. 13: Harmonic voltage compensation with ANFIS.

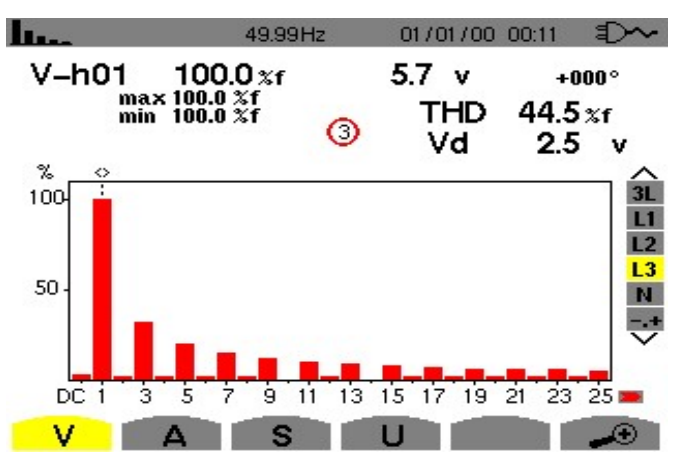

(a)
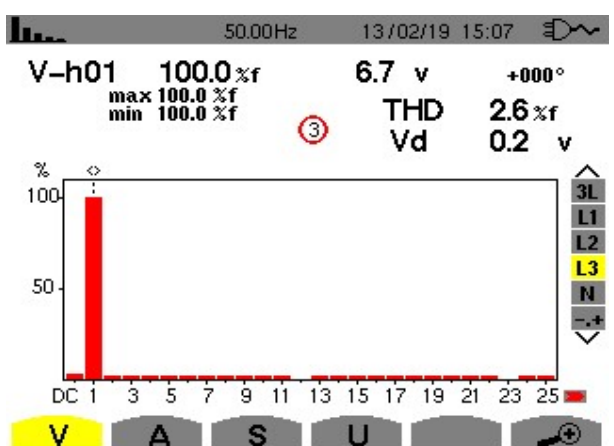

(b)

Fig. 14: Total harmonic distortion with ANFIS: (a) the source voltage, (b) load voltage.

Table 4 compares the THD values without and with control for the three controllers.

Table 4: Comparison of the two controllers in the experimental tests.

\begin{tabular}{|c|c|c|}
\hline THD without control & \multicolumn{2}{|c|}{ THD with control } \\
\hline \multirow{2}{*}{$44.55 \%$} & BSMC & ANFIS \\
\cline { 2 - 3 } & $3.5 \%$ & $2.6 \%$ \\
\hline
\end{tabular}

It can be observed that the THD is reduced to $3.5 \%$ with SMC and $2.6 \%$ with ANFIS. This demonstrates the effectiveness of ANFIS-based controlled as compared BSMC.

\section{CONCLUSION}

This paper presented a simulation study and a real-time validation of a single-phase SAPF (Series Active Power Filter) with two different control schemes based on Back-Stepping Sliding Mode Control (BSMC) and neurofuzzy control based on ANFIS (Adaptive Neuro-Fuzzy Inference System). The SAPF was able to effectively compensate the voltage harmonics to satisfy the international IEEE standards (IEEE 519-1992 and IEEE 1159- 
1995). The two control strategies have been compared under various fault conditions and ANFIS-based controller has demonstrated improved performance in terms of THD values of the voltage output waveforms. In addition, ANFIS-based controller gave a faster transient response than BSMC. The proposed control strategies have been successfully validated experimentally on a laboratory-scale SAPF prototype. Both BSMC and ANFIS were able to enhance the performance of the SAPF and mitigate harmonics to produce improved quality of the voltage waveforms. The control scheme with ANFIS gave improved performance and robustness. Based on the performance analysis, it can be concluded that the SAPF makes the most economical with a compact size and can provide very effective compensation for the problem of harmonics. It can be used in all places where the harmonic problem arises.

As future work, the authors propose to design and develop a parallel-serial topology (Unified Power Quality Conditioner (UPQC)) given the many advantages they offer, including voltage and current harmonics filtering. Other voltage inverters with multilevel topologies produce enhanced voltage waveforms and therefore give an improved spectral performance of the output quantities and increase its power. Finally, the use of rectifier-based power sources powered from the voltage source and associated with a controller whose role is to regulate DC voltage can also be investigated.

\section{Acknowledgements}

The authors are thankful to the General Direction of Scientific Research and Technological Development, DGRSDT for providing a research grant.

\section{REFERENCES}

[1] RC Dugan, HW Beaty, MF McGranaghan, "Electrical power systems quality”, 2nd ed. McGraw Hill; 2002.

[2] A. Kusko, MT. Thompson "Power quality in electrical systems", McGraw Hill; 2007.

[3] J.S. Subjak, J.S. Mcquilin, "Harmonics-Causes, Effects, Measurements and Analysis”, IEEE Transactions on Industry Applications, Vol. 26, No. 6, pp. 1034-1042, 1990.

[4] W. Tongzhen, J. Dongqiang, "Analysis and evaluation of the fault current limiting function of series custom power devices", 23-27 Oct. 2011 first International Conference on Electric Power Equipment - Switching Technology.

[5] K. Alexander, and Marc T. Thompson, "Power Quality in Electrical Systems", McGraw-Hill.2007.

[6] N. Zaveri, A. Chudasama, "Electrical Power and Energy Systems Control strategies for harmonic mitigation and power factor correction using shunt active filter under various source voltage conditions", Int. J. Electr. Power Energy Syst., vol. 42, no 1, pp. 661-671, 2012.

[7] M. Basu, S.P. Das, G.K. Dubey, "Performance study of UPQC-Q for load compensation and voltage sag mitigation", Conference of the Industrial Electronics Society.Vol.1, pp.698-703, 2002.

[8] J.C. Das, "Passive filters-potentialities and limitations", IEEE Trans. Ind. Appl. 40(1) (2004), pp: $232-241$.

[9] L. Moran, P. Werlinger, J. Dixon “A Series Active Power Filter which Compensates Current Harmonics an Voltage Unbalance Simultaneously”, IEEE Power Electronics Specialists Conference, PESC'95, Atlanta, Georgia, USA, pp. 222-227. 
[10] H. Kevork, G. Joos, "A fast algorithm for voltage unbalance compensation and regulation in faulted distribution systems", Proceeding of the IEEE Conference on Applied Power Electronics and Exposition, pp. 963-969, 1998.

[11] M. Chovatia Chandani, P. Gupta Narayan, Preeti N. Gupta, "Power Quality Improvement in a PV Panel connected Grid System using Shunt Active Filter”, IJCTEE, International Journal of Computer Technology and Electronics Engineering, Vol. 2, Issue 4, August 2012.

[12] C. Sankaran, "Power Quality", CRC Press LLC New York, 2002.

[13] K. Sudheer, R. Sudha, "Effective Grid Interfaced Renewable Sources with Power Quality Improvement using Dynamic Active Power Filter", INT J Elec Power, 2016.

[14] S Ravi, Vitaliy Mezhuyev, K Iyswarya Annapoorani, P Sukumar, "Design and implementation of a microcontroller based buck boost converter as a technology and Electronics Engineering”, (IJCTEE) Vol. 1, Issue 3, mars 2016, pp: 566-574.

[15] M.H.J. Bollen, "Understanding power quality problems: voltage sags and interruptions": IEEE press New York, 2000.

[16] P.V. Manitha, S. Raji and G. Nair Manjula, "Performance Analysis of Different Control Algorithms for Series Active Filter", 2015 IEEE International Conference on Electrical, Computer and Communication Technologies (ICECCT), pp: 1-7.

[17] A. BenAbdelkader, O. Abdelkhalek and A. Allali. "Experimental validation of single-phase series active power filter using fuzzy control technique”. IJPEDS, 2018, International Journal of Power Electronics and Drive Systems, vol. 9, no. 2, pp. 591-601.

[18] X. Zhang, X. Liu, Y. Li. Adaptive fuzzy tracking control for nonlinear strict-feedback systems with unmodeled dynamics via backstepping technique. Neurocomputing, 235, 182- 191 ,2017. 18.

[19] L. Niu, Adaptive Backstepping-Based Neural Tracking Control for MIMO Nonlinear Switched Systems Subject to Input Delays. IEEE Trans. on Neural Networks and Learning Systems. 25(1):126-139, 2017. 19.

[20] Y. Hou, S. Tong. Command filter-based adaptive fuzzy backstepping control for a class of switched nonlinear systems. Fuzzy Sets \& Systems.314: 46-60, 2016. 20.

[21] A. Pandey, R. Agrawal, R. S. Mandloi and B. Sarkar. "Sliding Mode Control of Dynamic Voltage Restorer by Using a New Adaptive Reaching Law”. Journal of The Institution of Engineers (India): Series B, vol. 98, no. 6, pp. 579-589, 2017

[22] R.R. Errabelli, Y.Y. Kolhatkar, S.P. Das, Experimental investigation of DVR with sliding mode control, in IEEE Power India Conference, 2006.

[23] T. Toumi, A. Allali, O. Abdelkhalek, A. BenAbdelkader, A. Meftouhi, M. A. Soumeur, "PV Integrated single-phase dynamic voltage restorer for sag voltage, voltage fluctuations and harmonics compensation”. IJPEDS, 2020, International Journal of Power Electronics and Drive Systems, vol. 11, no. 1, pp547-554

[24] Y. Chang, L. Jinjun, W. Xiaoyu and W. Zhaoan. "A novel control of series active power filter without harmonics detection”. In Power Electronics Specialists Conference, 2007. PESC 2007. IEEE, pp. 1112-1115.

[25] J. Jang, “ANFIS: adaptive network-based fuzzy inference systems”. IEEE 1993 Transactions on Systems, Cybernetics 23(03), pp: 665-685.

[26] X. Lou and K. A. Loparo, "Bearing fault diagnosis based on wavelet transform and fuzzy inference," Mechanical Systems and Signal Processing, Elsevier. 2004, vol. 18. 
[27] K. Sudheer, R. Sudha, "Hybrid Fuzzy-ZN PID control based Grid Interfaced distribution level Renewable Energy Source with Power Quality”, ICCPCT, IEEE, pp.1-7, Mar 2015

\section{Appendix A}

The layer structure of ANFIS is depicted in Fig. A1.

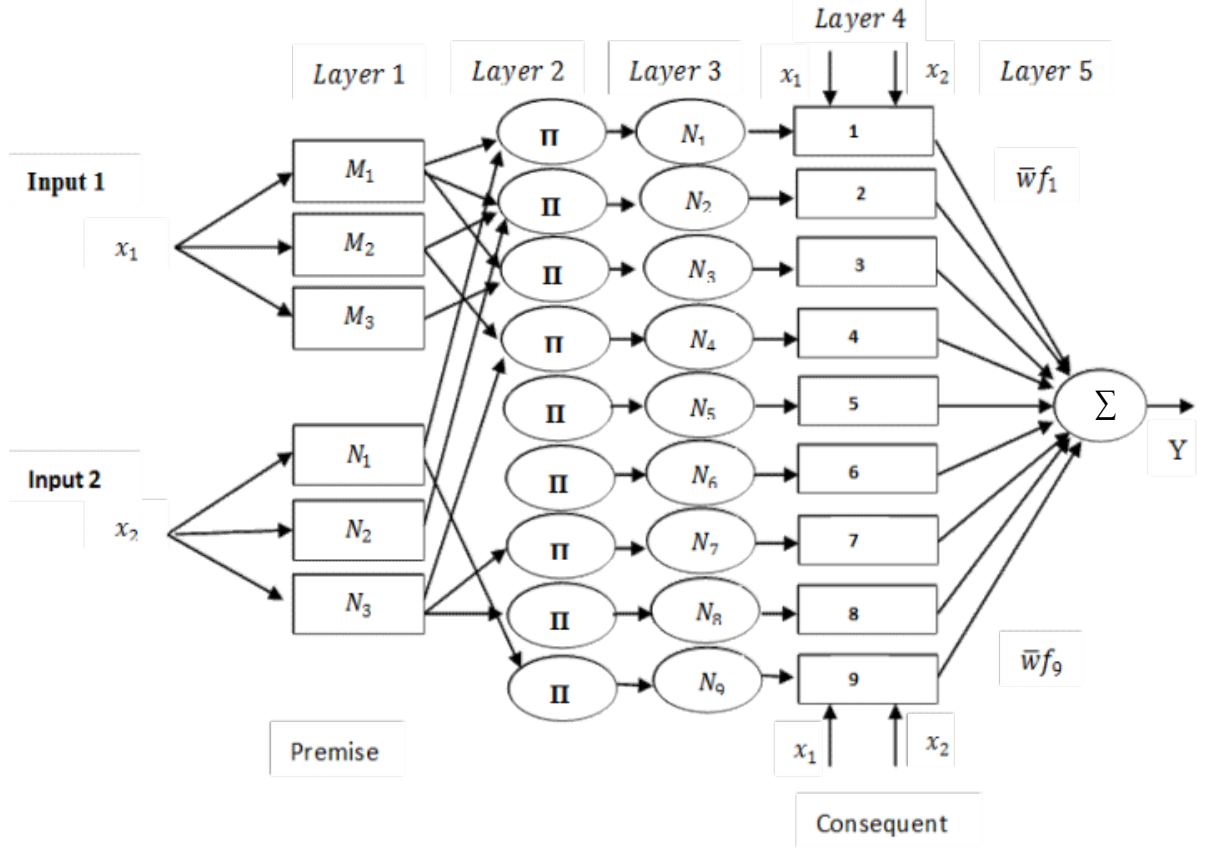

Fig. A1 Structures of ANFIS.

There are two inputs: input $1\left(x_{1}\right)$ and input $2\left(x_{2}\right)$ and each layer consists of nodes. ANFIS consists of adaptive nodes (square-shape) and fixed nodes (circle-shape).

Layer 1: $x_{1}$ is the input to node $i$, and $A_{i}$ is the linguistic label $\left(M_{1}, M_{2}, M_{3}\right)$ associated with this node. The membership functions used here are triangular. The node equations are given below:

$$
\begin{aligned}
& Q_{i}^{1}=\mu M_{i}\left(x_{1}\right) \\
& \mu M_{i}\left(x_{1}\right)= \begin{cases}0 & x_{1} \leq a_{i} \text { or } c_{i} \leq x_{1} \\
\frac{x_{1}-a_{i}}{b_{i}-a_{i}} & a_{i} \leq x_{1} \leq b_{i} \\
\frac{c_{i}-x_{1}}{c_{i}-b_{i}} & b_{i} \leq x_{1} \leq c_{i}\end{cases}
\end{aligned}
$$

Where, $i=1,2,3, Q_{i}^{1}$ is the output of the $\mathrm{i}^{\text {th }}$ node and $a_{i}, b_{i}, c_{i}$ denotes the parameters of the triangular membership functions.

Layer 2: this layer multiplies the incoming signals and transmit them to Layer 3.

$$
W_{j}=\mu M_{i}\left(x_{1}\right) * \mu N_{i}\left(x_{2}\right)
$$

Where $i=1,2,3$ and $j=1,2, \cdots, 9$.

The output from each node is the firing strength of a rule. 
Layer 3: The output of this layer calculates the normalized firing strength of every rule

$$
\bar{W}_{j}=\frac{W_{j}}{\sum_{K=1}^{9} W_{K}}
$$

Where, $j=1,2, \cdots, 9$.

Layer 4: The parameters of this layer are called consecutive parameters. The output of the node is a weighted sum of these intermediate outputs:

$$
O_{j}^{4}=\bar{W}_{j} f_{j}=\bar{W}_{j}\left(p_{j} x_{1}+S_{j} x_{2}+t_{j}\right)
$$

ANFIS's rule is written as:

$$
\text { if } x_{1} \text { is } A_{n} \text { and } x_{2} \text { is } B_{n} \text { then } f_{n}=p_{n} x_{1}+S_{n} x_{2}+t_{n}
$$

Where $n=1,2, \cdots, 9$ and

$O_{j}^{4}=$ Output of the $\mathrm{j}^{\text {th }}$ node of Layer 4 .

$\bar{W}_{j}=$ output from Layer 3.

$M_{i}, N_{i}=$ fuzzy membership functions

$i=1,2, \cdots, 7$ and $j=1,2, \cdots, 49$.

Layer 5: This layer has only one node represented by a circle. The output $Y$ of this layer is the sum of all incoming signals.

$$
Y=O_{i}^{5}=\sum_{i} O_{i}^{4}
$$

The parameter of adaptive nodes changes during the training process. Equation (A.6) gives the overall output of the ANFIS model.

\section{Appendix B}

Table B1. Parameters values of the simulation model and hardware setup.

\begin{tabular}{ll}
\hline \hline Parameters & Values \\
\hline \hline Source voltage frequency, $\boldsymbol{f}$ & $50 \mathrm{~Hz}$ \\
\hline Source voltage, $\boldsymbol{V}_{\boldsymbol{s}}$ & $7.3 \mathrm{Vrms}$ \\
\hline Load resistance, $\boldsymbol{R}_{\boldsymbol{L}}$ & $12.3 \Omega$ \\
\hline LC filter capacitance, $\boldsymbol{C}_{\boldsymbol{f}}$ & $1 \mathrm{nF}$ \\
\hline LC filter inductance, $\boldsymbol{L}_{\boldsymbol{f}}$ & $9 \mathrm{mH}$ \\
\hline Transformer & $12 \mathrm{~V} / 230 \mathrm{~V} / 1 \mathrm{kVA}$ \\
\hline DC-bus capacitor & $2200 \mu \mathrm{F}$ \\
\hline Reference voltage, $\boldsymbol{V}_{\boldsymbol{d} \boldsymbol{c}}^{*}$ & $24.1 \mathrm{~V}$ \\
\hline PI gains (simulations) & $K_{p}=7.2, K_{i}=33$ \\
\hline PI gains (experimental) & $K_{p}=8.8, K_{i}=4.24$ \\
\hline Sliding mode controller parameters & $k_{1}=250, k_{2}=0.023, \alpha=57, \beta=400, \gamma=0.001, k=0.01$ \\
\hline
\end{tabular}




\section{Appendix C}

Details of the Simulink implementation of SAPF connected to the distribution grid and the Backstepping Sliding Mode controller are depicted in Figs. $\mathrm{C} 1$ and $\mathrm{C} 2$ respectively.
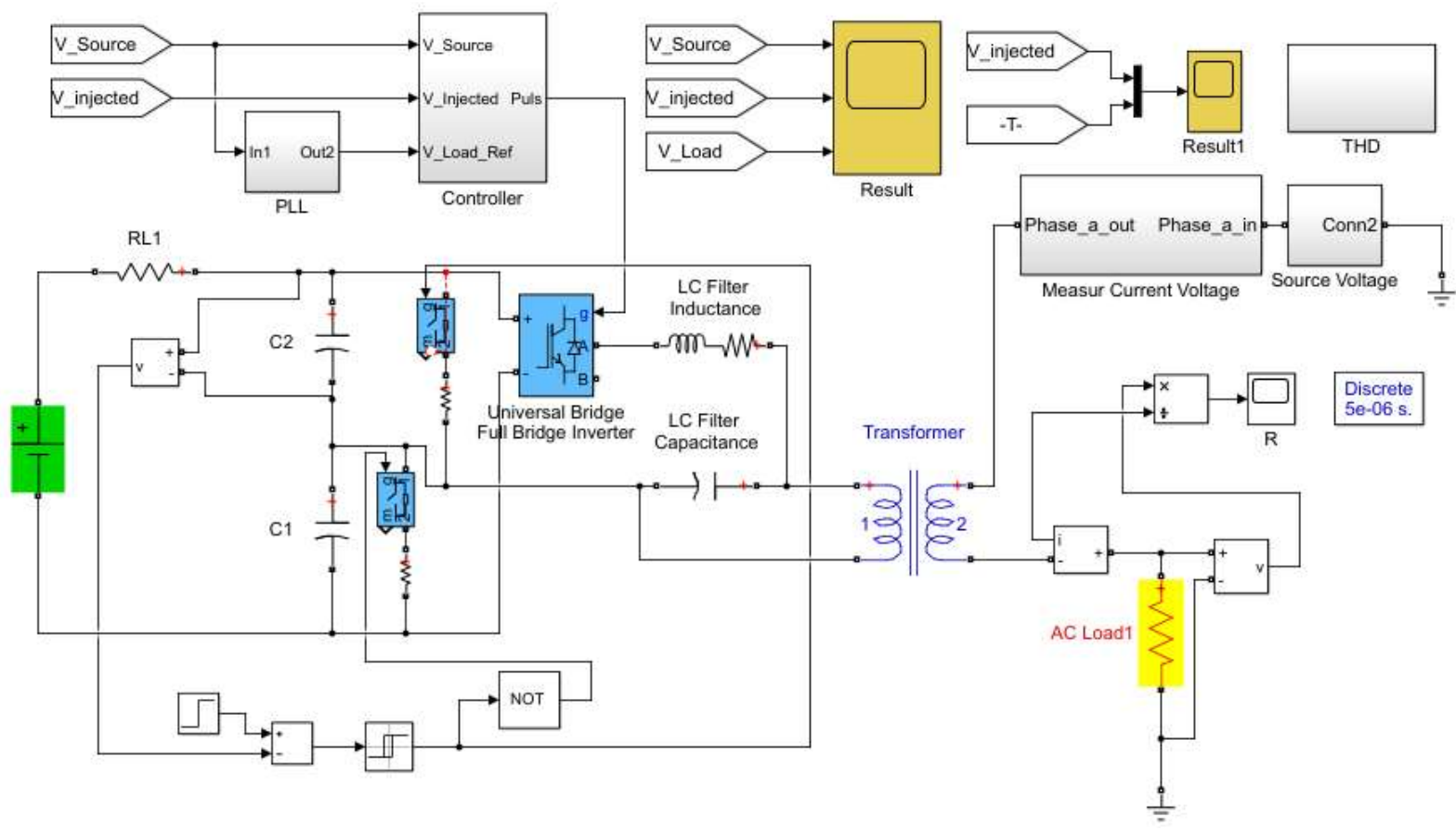

Fig. C1 Simulink model of the SAPF connected to the grid.

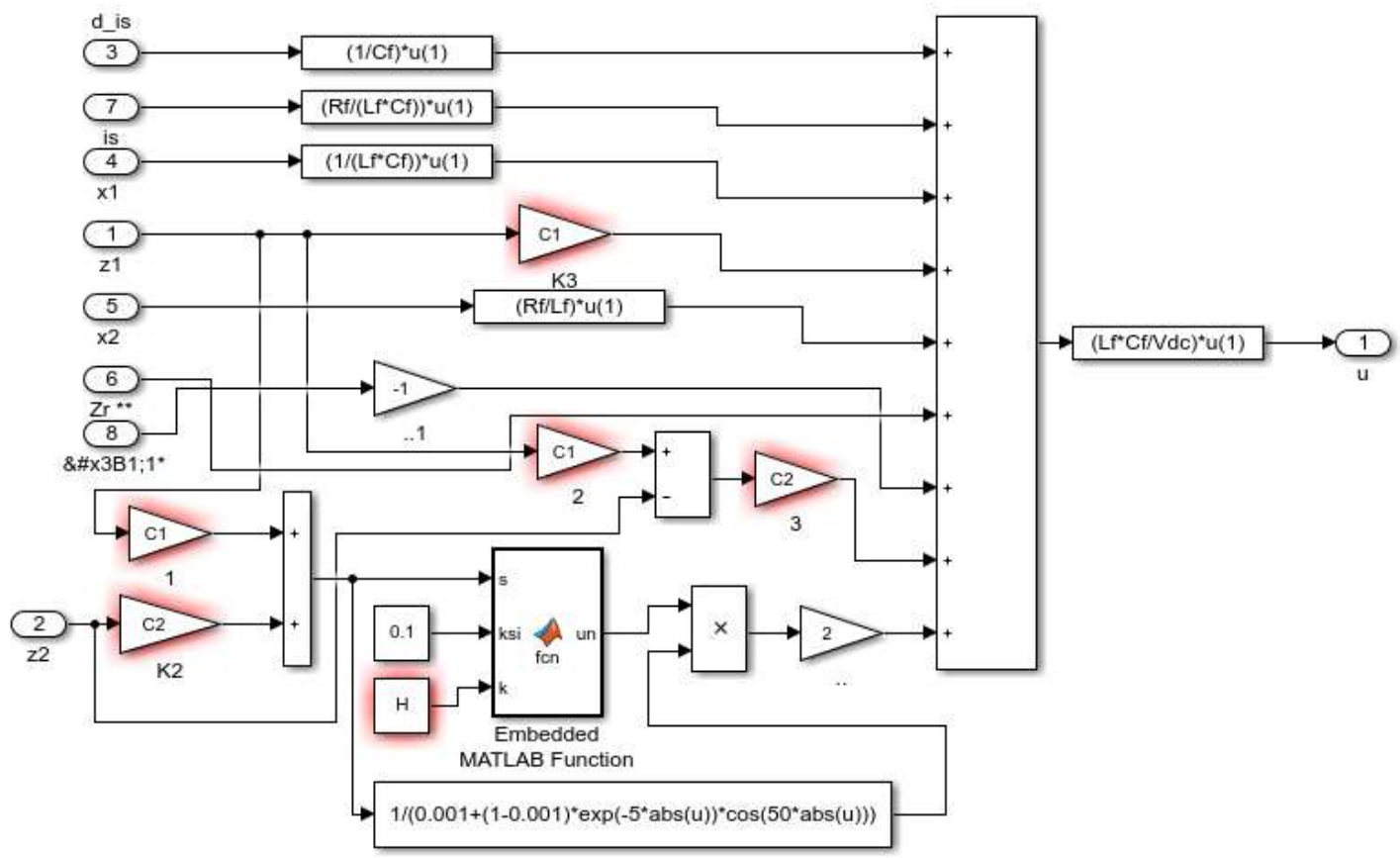

Fig. C2 Simulink model of the BSMC. 